\title{
Retrospective Evaluation of Risk Factors for Invasive Candida Infections in a Medical Intensive Care Unit
}

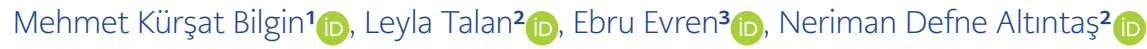 \\ 1 Tokat Erbaa State Hospital, Tokat, Turkey \\ 2 Department of Internal Medicine, Division of Intensive Care, Ankara University School of Medicine, Ankara, Turkey \\ 3 Department of Microbiology, Ankara University School of Medicine, Ankara, Turkey
}

\begin{abstract}
Objective: We aimed to detect the risk factors for invasive candida infections by evaluating the fungal strains cultivated from samples taken in a medical intensive care unit (ICU).

Materials and Methods: We investigated fungal growths between January 1, 2016, and December 1, 2018, retrospectively. All reported fungal growths and demographic characteristics, clinical features, treatments and outcomes of the patients with fungal growths were recorded.

Results: Fungal growths were reported from 384 different samples obtained from 179 ICU patients. The most common strain was determined to be C. albicans (47.9\%). The incidence of non-albicans Candida strains was increased over the years (2016 - 44\%, $2017-52.5 \%$, $2018-49 \%)$, most significantly C. glabrata (7.7\% to $14.6 \%)$. The most common strain was C. parapsilosis $(57.9 \%)$ in patients with candidemia, and infection was more severe among them. Fluconazole resistance was rare. When patients with and without fungal growth were compared, a significant difference was found between groups in terms of age, acute physiology and chronic health evaluation II (APACHE II) score, length of ICU and hospital stay, ICU and hospital mortality $(p<0.001, p=0.011, p<0.001, p=0.031, p=0.016)$. Candida score was significantly higher in candidemic patients (3.0 vs $0.0 p<0.001)$.

Conclusion: Among fungal growths in samples from critically ill patients, the incidence of non-albicans Candida strains was gradually increasing. Older age, higher APACHE II score, and longer hospital and ICU stay were associated with fungal growths.
\end{abstract}

Keywords: candidemia; candida score; c. parapsilosis; intensive care unit
Corresponding Author: Leyla Talan

E-mail:

leylatalan@gmail.com

Received: June 15, 2021

Accepted: October 16, 2021

Published: February 14, 2022

Suggested citation: Bilgin MK, Talan L, Evren E, Altıntaş ND. Retrospective evaluation of risk factors for invasive candida infections in a medical intensive care unit. Infect Dis Clin Microbiol 2022; 1.

DOI: 10.36519/idcm.2022.56 


\section{INTRODUCTION}

F ungal infections account for about $20 \%$ of all microbiological infections in critically ill patients (1). Candida species are the most common fungi in intensive care units (ICU) and mostly C. albicans (1-3). However, the rate of non-albicans Candida species such as C. tropicalis, C. krusei, C. parapsilosis, C. glabrata which are more resistant to antifungal therapy, has been increasing rapidly in recent studies $(1,2,4,5)$.

The rise of fungal infections in critically ill patients can be related to the presence of advanced age, prolonged length of ICU stay, glucocorticoid or immunosuppressive drug use, diabetes mellitus (DM), multiple invasive procedures, renal replacement therapy (RRT), and the wide use of invasive devices (central venous catheter [CVC]). In addition, many ICU patients are treated with prolonged antibiotic therapies for real or presumed bacterial infections, favouring the onset of fungal infections $(2,4-6)$.

Candida species are found in the normal flora of the mucous membranes of the skin, gastrointestinal tract (GIS), genitourinary system (GUS) and respiratory system in humans. Colonization is most common in the oesophagus and can become an invasive disease in $3-25 \%$ (1). In order to distinguish between colonization and infection, tissue biopsy is required under ideal conditions. However, since the procedure is invasive, it is suggested that the Candida score may also be used to estimate the presence of infection (2,4-6). This study aimed to evaluate the fungal strains cultivated from samples taken in a medical ICU and detect risk factors for invasive Candida infections.

\section{MATERIALS AND METHODS}

\section{Patients and Data Extraction}

Patients admitted to the third level ICU of a university hospital between January 1, 2016, and December 1, 2018, were included in the study if at least one of their cultures was positive for fungal infection during ICU stay.

Routine surveillance culture screening is not performed in our ICU. Microbiological sampling is per- formed only in the presence of clinical or laboratory signs of infection. These signs include fever, clinical deterioration, elevated acute phase reactants, hemodynamic instability, presence of purulent secretions, redness/pus around any catheter entry area, and development of symptoms suggesting sepsis.

If patients with candiduria have an indwelling Foley catheter, repeat urine cultures are required after changing the catheter. Antifungal therapy is initiated in patients with positive urine cultures if clinical findings of urinary tract infection are present or repeat urine cultures are positive. Antifungal treatment is also administered in patients as an empirical/pre-emptive therapy if they have a high Candida score or are septic and have risk factors.

If a patient has a suspected catheter infection or a positive culture, the catheter is removed as soon as possible. The catheter tip is sent for microbiological examination if there is no contraindication to remove the catheter. Echocardiography, hepatobiliary ultrasonography and ocular examination are performed as soon as possible for all patients with candidemia.

In the case of a positive culture, the patient is evaluated by his doctor, an intensivist and the consulting infectious disease specialist to plan treatment in a consensus. The patients' data included in the study were obtained by examining the intensive care files and laboratory data via the hospital's electronic database. Patient's age, admission diagnoses, Charlson comorbidity index (CCI), ICU and hospitalization admission and exit dates, presence of a solid tumor or hematological cancer, radiotherapy or chemotherapy treatment, immunosuppressive therapy, steroid use before or during ICU, presence of central

\section{HIGHLIGHTS}

- The incidence of non-albicans strains among candida growths has been increasing over the years.

- Age, APACHE II score, duration of hospital and ICU stay were associated with fungal growths.

- Candida score was predictive of candidemia. 
venous catheter (CVC) or urinary catheter, invasive mechanical ventilation (IMV) requirement, need for renal replacement therapy (RRT), total parenteral nutrition (TPN) administration, presence of abdominal surgery, APACHE II score, sequential organ failure assessment (SOFA) score, and Candida score were recorded. Moreover, the types of fungal strains, sampling site and presence of multifocal colonisation, results of antibiotic susceptibility testing and the antifungal agents administered and their adequacy were recorded to the database. In addition, C-reactive protein (CRP) and procalcitonin levels, body temperature and antibiotic therapy when samples were obtained were recorded in the pre-prepared patient registration form.

\section{Microbiology}

The samples taken from patients were plated on blood agar (Oxoid, UK), MacConkey agar (Oxoid, UK) for bacterial growth and incubated at $37^{\circ} \mathrm{C}$ for $24-48$ hours in ambient air and chocolate agar at $37^{\circ} \mathrm{C}$ for 24 48 hours in $\mathrm{CO} 2$ air. In addition, sabauraud dextrose agar (Oxoid, UK) and potato dextrose agar (Oxoid, UK) were used for fungal growth, incubated both at room temperature and $37^{\circ} \mathrm{C}$ at least for five days.

Yeast identification was made with cornmeal agar with Tween ${ }^{\circledR} 80$ (Oxoid, UK) for determining the Candida chlamydospore morphology and MALDI-TOF MS system (Bruker Daltonics, Germany).

Candida albicans ATCC 90028 and Candida parapsilosis ATCC 22019 were used as the quality control strains.

Antifungal susceptibility testing was performed by broth dilution method according to European Committee on Antimicrobial Susceptibility Testing (EUCAST) recommendation.

\section{Statistical Analysis}

The research data was evaluated through the Statistical Package for Social Sciences (SPSS) 22.0 (IBM Corp., Armonk, NY, USA). Descriptive statistics were presented as mean \pm standard deviation, median (interquartile range $[\mathrm{IQR}]$ ), frequency distribution and percentage. IQR are calculated by subtracting the 25 th percentile from the 75 th percentile. Pearson's chi-square test and Fisher's exact test were used to evaluating categorical variables. Visual (histogram and probability plots) and analytical methods (KolmogorovSmirnov test and Shapiro-Wilk test) were used to examine if the variables were distributed normally. Mann-Whitney U Test was used among the two independent groups for the variables that were not normally distributed, and the Kruskal Wallis test was used among the four independent groups. When a significant difference was detected, the Mann-Whitney U test with Bonferroni correction was used in the post-hoc binary comparisons for the source of the difference. If variables conformed to the normal distribution, we used Student's T-test between two independent groups and oneway ANOVA between four independent groups for statistical significance. When there was a significant difference, Tukey's HSD test was used in post-hoc binary comparisons.

Independent predictors in predicting candidemia development status and pre-emptive treatment status using possible factors determined in previous univariate analyses were analyzed using logistic regression analysis. In addition, we evaluated model fit by the Hosmer-Lemeshow test. Statistical significance was set as $p<0.05$.

\section{RESULTS}

During the study period a total of 384 fungal growths were reported for 179 patients. Samples were collected from urine, endotracheal aspirate, peripheral blood and blood drawn from a catheter, catheter tip, sputum, wound, abscess and cerebrospinal fluid. The median age was 72 years (IQR:20), and $46.4 \%$ were women. The mean APACHE II score was $24.7 \pm 7.8$, and the median SOFA score was 6 (IQR: 5). The median length of ICU stay was 18 (IQR: 24) days.

Patients' admission diagnoses included acute respiratory failure (53.1\%), sepsis (46.4\%), and acute kidney injury (23.5\%). The most common comorbid disease was diabetes with end-organ damage (36.3\%). It was followed by coronary artery disease (34.6\%), congestive heart failure (32.4\%) and dementia (15.1\%). The median CCI was 7 (IQR: 4). As an infection risk factor, $87.2 \%$ of the patients were on invasive mechanical 
Table 1. Descriptive and clinical features of patients with fungal culture positivity.

\begin{tabular}{|c|c|}
\hline & $\mathrm{n}=179(\%)$ \\
\hline Age (years), median (IQR) & $72(20)$ \\
\hline Female & $83(46.4)$ \\
\hline APACHE II score, mean; SD & $24.7 \pm 7.8$ \\
\hline SOFA score, median (IQR) & $6(5)$ \\
\hline Length of ICU stay (days), median (IQR) & $18(24)$ \\
\hline \multicolumn{2}{|l|}{ Admission diagnosis } \\
\hline Acute respiratory failure & $95(53.1)$ \\
\hline Sepsis & $83(46.4)$ \\
\hline Acute kidney injury & $42(23.5)$ \\
\hline Infection & $36(20.1)$ \\
\hline Cardiac diseases & $14(7.8)$ \\
\hline Hepatic diseases & $14(7.8)$ \\
\hline Bleeding & $9(5.0)$ \\
\hline Others & $41(22.9)$ \\
\hline \multicolumn{2}{|l|}{ Comorbidities\# } \\
\hline Kidney disease & $65(36.3)$ \\
\hline Diabetes with end-organ damage & $65(36.3)$ \\
\hline Coronary artery disease & $62(34.6)$ \\
\hline Congestive heart failure & $58(32.4)$ \\
\hline Dementia & $27(15.1)$ \\
\hline Connective tissue disease & $24(13.7)$ \\
\hline Cerebrovascular disease & $24(13.7)$ \\
\hline Diabetes without end-organ damage & $16(8.9)$ \\
\hline Liver disease without portal hypertension & $16(8.9)$ \\
\hline Solid tumor without metastasis & $13(7.3)$ \\
\hline Leukaemia & $12(6.7)$ \\
\hline Peripheral vascular disease & $11(6.1)$ \\
\hline Hemiplegia & $10(5.6)$ \\
\hline
\end{tabular}

ventilation, $85.5 \%$ had an indwelling urinary catheter, and $59.8 \%$ had a central venous catheter (Table 1).

In 384 samples examined, C. albicans (184-47.9\%) were the most common strain revealed. It was

\section{(continue to Table 1)}

\begin{tabular}{|c|c|}
\hline Solid tumor with metastasis & $7(3.9)$ \\
\hline Liver disease with portal hypertension & $7(3.9)$ \\
\hline Peptic ulcer & $4(2.2)$ \\
\hline Lymphoma & $3(1.7)$ \\
\hline \multicolumn{2}{|l|}{$\begin{array}{l}\text { Risk factors for fungal culture } \\
\text { positivity\# }\end{array}$} \\
\hline Invasive mechanical ventilation & $156(87.2)$ \\
\hline Urinary catheter & $153(85.5)$ \\
\hline Central venous catheter & $107(59.8)$ \\
\hline Renal replacement therapy & $72(40.2)$ \\
\hline Septic shock & $61(34.1)$ \\
\hline Steroid treatment in ICU & $61(34.1)$ \\
\hline Multifocal colonization & $46(26.1)$ \\
\hline Steroid treatment before ICU admission & $40(22.3)$ \\
\hline Chronic obstructive pulmonary disease & $36(20.1)$ \\
\hline Total parenteral nutrition & $24(13.4)$ \\
\hline Immunosuppressive treatment & $21(11.7)$ \\
\hline Haematological malignancy & $19(10.6)$ \\
\hline End-stage renal disease & $21(11.7)$ \\
\hline Solid tumor & $19(10.6)$ \\
\hline Radiotherapy/Chemotherapy & $18(10.1)$ \\
\hline Neutropenia & $17(9.5)$ \\
\hline Abdominal surgery & $7(3.9)$ \\
\hline Solid organ transplant & $5(2.8)$ \\
\hline Stem cell transplant & $4(2.2)$ \\
\hline $\begin{array}{l}\text { Charlson comorbidity index, } \\
\text { median (IQR) }\end{array}$ & $7(4)$ \\
\hline
\end{tabular}

followed by other Candida species (46.8\%) and Aspergillus species and, in several cases, Trichosporon, Saccharomyces, Fusarium and Rhizopus (5.3\%). The frequency of Candida spp., which were the most common agents, by years is presented in Table 2 . 
Table 2. Candida strains revealed by years.

\begin{tabular}{|c|c|c|c|c|}
\hline $\mathrm{n}(\%)$ & 2016 & 2017 & 2018 & Total \\
\hline \multicolumn{5}{|l|}{ Candida species } \\
\hline C. albicans & $51(56.0)$ & $81(47.5)$ & $52(51.0)$ & $184(50.5)$ \\
\hline C. tropicalis & $13(14.3)$ & $23(13.4)$ & $11(10.8)$ & $47(12.9)$ \\
\hline C. glabrata & $7(7.7)$ & $13(7.6)$ & $15(14.6)$ & $35(9.6)$ \\
\hline C. parapsilosis & $10(11.0)$ & $23(13.4)$ & $10(9.8)$ & $43(11.8)$ \\
\hline C. kefyr & $8(8.8)$ & $5(2.9)$ & $12(11.8)$ & $25(6.9)$ \\
\hline C. Iusitaniae & 0 & $17(9.9)$ & $1(1.0)$ & $18(4.9)$ \\
\hline C. krusei & $1(1.1)$ & $9(5.3)$ & $1(1.0)$ & $11(3.0)$ \\
\hline C. dubliniensis & $1(1.1)$ & 0 & 0 & $1(0.3)$ \\
\hline Total & $91\left(25.0^{\star}\right)$ & $171\left(47.0^{\star}\right)$ & $102\left(28.0^{\star}\right)$ & $364(100)$ \\
\hline
\end{tabular}

* Percentage of rows

Antibiotic susceptibility testing was performed in $170(46.7 \%)$ of 364 Candida species. In these tests, apart from five C. krusei samples naturally resistant to fluconazole, fluconazole resistance was detected in 1 of 184 samples for C. albicans and 3 of 35 samples for C. glabrata. In addition, fluconazole susceptibility testing was performed in 14 of 19 patients with candidemia and no resistance to fluconazole was detected. Amphotericin B resistance was detected in $7 \%$ of Candida species. Candidemia was detected in 19 $(10.6 \%)$ of 179 patients. In these 19 patients, the most common causative agent was C. parapsilosis (57.9\%). Echinocandin resistance could not be evaluated during the study period because the antimicrobial agent was not available in our hospital.

Nineteen patients with candidemia were examined for the relationship between risk factors and Candida type. Most common risk factors noted were IMV ( $\mathrm{n}=18)$, CVC $(\mathrm{n}=13)$, RRT $(\mathrm{n}=11)$ and TPN $(\mathrm{n}=8)$. Septic shock accompanied candidemia in 11 patients, and C. parapsilosis positivity seemed more likely to present with septic shock.

When patients with and without candidemia were compared Candida score, CCI and length of ICU stay were determined as possible risk factors for the development of candidemia (Table 4). We performed multivariate logistic regression analysis to evaluate the independent effects of probable predictors determined as a result of univariate analysis in predicting the development of candidemia. As a result of this analysis, we found that length of ICU stay did not increase the risk of candidemia, and patients with higher candidemia scores and lower CCI were more likely to develop candidemia (Candidemia score: OR:1.93, 95\% CI:1.27-2.94, p:0.002; CCI: OR:0.77, 95\% CI:0.62-0.95, p:0.016). When patients, who were admitted to ICU during the same period, with (either colonization or infection) and without fungal growth were compared, a significant difference was found between the groups in terms of age, APACHE II score, length of ICU and hospital stay, ICU and hospital mortality ( $p$ $<0.05$ ) (Table 5).

\section{DISCUSSION}

Fungal infections have increased rapidly in the last few decades (7). Infections related to Candida species are seen more frequently in ICUs. These infections are associated with $47 \%$ mortality (8). Many risk factors have been identified for the development of candida infections, such as broad-spectrum antibiotic treatment, hemodialysis, pancreatitis, TPN and treatment with steroids or other immunosuppressive agents (9). Despite new antifungal agents and advanced care, candidemia is associated with increased medical cost, mortality 
Table 3. Features associated with candidemia risk factors.

\begin{tabular}{|l|c|}
\hline Risk factor & $\mathrm{n}=19(\%)$ \\
\hline TPN & $8(42.1)$ \\
\hline Abdominal surgery & $2(10.5)$ \\
\hline Multiple colonization & $12(63.2)$ \\
\hline IMV & $18(94.7)$ \\
\hline CVC & $13(68.4)$ \\
\hline RRT & $11(57.9)$ \\
\hline COPD & $4(21.1)$ \\
\hline Immunosuppressive treatment & $3(15.8)$ \\
\hline Steroid therapy & $6(31.6)$ \\
\hline before ICU & $7(36.8)$ \\
\hline Steroid therapy in ICU & $1(5.3)$ \\
\hline Solid tumor & $4(21.1)$ \\
\hline Haematological malignancy & $11(57.9)$ \\
\hline Radiotherapy/ Chemotherapy & $16(84.2)$ \\
\hline Stem-cell transplant & $2(10.5)$ \\
\hline Septic shock & \\
\hline Urinary catheter & \\
\hline End-stage renal disease & \\
\hline
\end{tabular}

COPD: Chronic obstructive pulmonary disease,

CVC: Central venous catheter,

ICU: Intensive care unit,

IMV: Invasive mechanical ventilation,

RRT: Renal replacement therapy,

TPN: Total parenteral nutrition,

and long-term hospitalization (10). A change in the pattern of infecting strains from $C$. albicans to non-albicans Candida species, such as C. glabrata, C. tropicalis, C. parapsilosis and C. krusei, is noted (11). In the EPCAN observational study evaluating 956 positive fungal cultures, the most common strain was Candida spp. (94.1\%) (12). In a thesis study evaluating candidemia in non-neutropenic ICU patients in our university, C. albicans was observed at a rate of $50.7 \%$ (13). In our study, C. albicans was the most common strain, followed by C. tropicalis and C. parapsilosis. The increasing frequency of C. glabrata over the years was also remarkable. Patients with a high probability of invasive candidiasis, that is, patients with more comorbidities and who are clinically septic, are empirically administered antifungal treatment while waiting for culture results. For some patients, fungal growth was reported only from tracheal aspirate or urine samples, and antifungal treatment was discontinued in those patients who were not considered to have a fungal infection. Positivity of the tracheal aspirate sample was not considered a diagnostic feature alone for fungal infection for any of the patients. These patients were considered to have fungal colonization.

In a recent multi-center study conducted in our countries ICU's, candidemia developed in $11.9 \%$ of colonized patients (14). In our study, the rate of development of candidemia after colonization was determined as $12 \%$. Therefore, colonized patients in the ICU should be carefully monitored, considering the risks of possible invasive candidiasis in the future. Recent epidemiological studies show an increase in candidemia because of $C$. parapsilosis $(15,16)$.

In our study, C. parapsilosis was observed as the most common agent in candidemia. A positive culture was detected in the first 72 hours in 5 of these patients. The incidence of increasing $C$. parapsilosis infections belongs to the organism's ability to grow in parenteral nutrition solutions and its tendency to form biofilms that lead to colonization of intravascular devices and prosthetic materials $(17,18)$. In our study, except for one patient, all of the patients who developed candidemia by C. parapsilosis had a $\mathrm{CVC}$, which is considered a risk factor for positive $\mathrm{C}$. parapsilosis culture.

Seventy-two percent of patients who developed candidemia due to C. parapsilosis were in a septic shock when samples were obtained. It was thought that septic shock may have developed early during the infection since it was related to an intravascular device.

Procalcitonin value below $<2.00 \mathrm{ng} / \mathrm{ml}$ is one of the findings that may help in the early differential diagnosis between candidemia and bacteremia (19). In the current study, the mean procalcitonin value in patients with candidemia was $1.5 \mathrm{ng} / \mathrm{ml}$ accordingly. 
Table 4. Distribution of some descriptive and clinical features among patients with and without candidemia.

\begin{tabular}{|l|c|c|c|}
\hline & $\begin{array}{c}\text { Candidemia } \\
(\mathrm{n}=19)\end{array}$ & $\begin{array}{c}\text { Candidal growth in any sample } \\
\text { without candidemia }(\mathrm{n}=138)\end{array}$ & $p$ \\
\hline Age (years), median (IQR) & $67.0(32)$ & $73.0(16)$ & $0.118^{\mathrm{a}}$ \\
\hline Female, $\mathrm{n}(\%)$ & $10(52.6)$ & $68(49.3)$ & $0.784^{\mathrm{b}}$ \\
\hline APACHE II, mean \pm SD & $26.9 \pm 8.5$ & $24.1 \pm 7.7$ & $0.150^{\mathrm{c}}$ \\
\hline SOFA, median (IQR) & $7.0(5)$ & $6.0(5)$ & $0.523^{\mathrm{a}}$ \\
\hline Candida score, median (IQR) & $3.0(3)$ & $0(2)$ & $<0.001^{\mathrm{a}}$ \\
\hline CRP (at sampling time), median (IQR) & $93.6(97.6)$ & $86.0(118.7)$ & $0.986^{\mathrm{a}}$ \\
\hline Procalsitonin (at sampling time), median (IQR) & $1.5(7.6)$ & $0.8(3.1)$ & $0.154^{\mathrm{a}}$ \\
\hline Length of ICU stay (days) & $27.0(49)$ & $18.0(22)$ & $0.026^{\mathrm{a}}$ \\
\hline Length of hospital stay (days) & $45.0(46)$ & $36.0(33)$ & $0.145^{\mathrm{a}}$ \\
\hline ICU mortality & $10(52.6)$ & $44(31.9)$ & $0.074^{\mathrm{b}}$ \\
\hline Hospital mortality & $12(63.2)$ & $55(39.9)$ & $7.0(3)$ \\
\hline Charlson comorbidity index, median (IQR) & $5.0(3)$ & & $0.054^{\mathrm{b}}$ \\
\hline
\end{tabular}

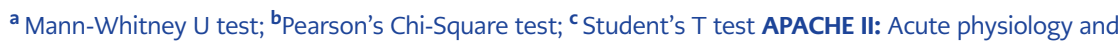
chronic health evaluation II, CRP: C-reactive protein, ICU: Intensive care unit, IQR: Interquartile range, n: Patient number, \%: Percentage, SD: Standard deviation, SOFA: Sequential organ failure assessment

In the study conducted by Al-Dorzi et al. in 2018, it was found that $42.9 \%$ of patients with suspected candidemia were administered empirically antifungal treatment and caspofungin was the most frequently used agent (20). In our study, $68.4 \%$ of the patients with candidemia were administered antifungal treatment considering the clinical and laboratory data before the blood culture result was reported. No significant difference was found in the APACHE II and SOFA scores, mortalities and length of stay of the patients administered empirical or targeted therapy. It was known that early antifungal treatment decreases mortality and shortens the length of stay in patients with candidemia. However, we did not find a significant difference in this study due to the small number of patients with candidemia.

The European Society of Clinical Microbiology and Infectious Diseases (ESCMID) and the Infectious Diseases Society of American (IDSA) 2016 guidelines no longer recommend the use of fluconazole in first-line therapy for invasive candidiasis and recommends the use of echinocandins as primary care empirical therapy $(4,21)$. In the present study, we observed that caspofungin was preferentially administered in septic patients with candidemia in accordance with the literature and current guidelines. However, the validity of this recommendation should be reviewed regarding local resistance patterns because strains' resistance against fluconazole was lower than the literature indicated.

It is stated that de-escalation is a safe choice in ICU, whereas improper treatment at the time of diagnosis prolongs ICU stay and increases mortality (22). Yet, in our study only one patient's systemic antifungal therapy was de-escalated to fluconazole.

In another study conducted by Jordà - Marcosve et al., the ICU mortality rate was $54 \%$ in candidemic patients, while $29.4 \%$ in patients without candidemia (23). In our study, the ICU mortality rate was $52.6 \%$ in patients with candidemia and $23.8 \%$ in patients without any fungal growth. APACHE II scores and length of ICU stay were significantly higher in patients with candidemia than patients without fungal growth. The higher mortality rate, 
Table 5. Distribution of some descriptive and clinical features of patients with candidemia, candida urinary tract infection, candidal colonization and patients without any fungal growth.

\begin{tabular}{|c|c|c|c|c|c|}
\hline & $\begin{array}{l}\text { Candidemia } \\
(\mathrm{n}=19)\end{array}$ & $\begin{array}{c}\text { Antifungal treatment } \\
\text { due to candiduria }(n=28\end{array}$ & $\begin{array}{l}\text { Colonization } \\
(n=111)\end{array}$ & $\begin{array}{c}\text { Without positive } \\
\text { fungal culture }(n=293\end{array}$ & $p$ \\
\hline Age (years), median (IQR) & $67.0(32)$ & $72.0(20)$ & $73.0(16)^{\text {ad }}$ & $67.0(24)$ & $<0.001^{1}$ \\
\hline Female, $n(\%)$ & $10(52.6)$ & $31(47.7)$ & $42(44.2)$ & $132(45.1)$ & $0.896^{2}$ \\
\hline $\mathrm{APACHE} I I$, mean $\pm \mathrm{SD}$ & $26.9 \pm 8.5$ & $25.2 \pm 6.7$ & $23.8 \pm 8.0$ & $21.7 \pm 9.5(n=245)^{a}$ & $0.011^{3}$ \\
\hline Length of ICU stay (days) & $27.0(49)$ & $11.0(19)$ & $19.0(23)$ & $7.0(11)^{\mathrm{abc}}$ & $<0.001^{1}$ \\
\hline Length of hospital stay (days) & $45.0(46)$ & $37.0(24)$ & $35.5(34)$ & $23.0(30)^{\mathrm{abc}}$ & $<0.001^{1}$ \\
\hline CU mortality & $10(52.6)$ & $10(35.7)$ & $30(27.3)$ & $70(23.9)$ & $0.031^{2}$ \\
\hline Hospital mortality & $12(63.2)$ & $10(25.7)$ & 37 (33.6) & $84(28.7)$ & $0.016^{2}$ \\
\hline
\end{tabular}

APACHE II: Acute physiology and chronic health evaluation II, ICU: Intensive care unit, IQR: Interquartile range, n: Patient number, $\%$ : Percentage, SD: Standard deviation. ${ }^{1}$ Kruskal Wallis test; ${ }^{2}$ Pearson Chi-Square test; ${ }^{3}$ ANOVA;

a There was a significant difference in post hoc binary comparison with 'candidemia';

b There was a significant difference in post hoc binary comparison with 'receiving antifungal treatment due to candiduria';

c There was a significant difference in post hoc binary comparison with 'colonization';

d There was a significant difference in post hoc binary comparison with 'without positive fungal culture.'

APACHE II score and length of ICU stay in patients with candidemia may be due to high-risk factors and comorbid conditions as well as disease severity. A significant difference was found in multivariate analysis between Candida scores of patients with candidemia and without candidemia. It is known that Candida score can be an important parameter in determining the risk of invasive candidiasis. In our study, Candida score was found to be higher in patients with candidemia.

Our study had some limitations. Firstly, since it was a retrospective study, some patients' data could not be accessed. Secondly, the contemporaneous positive bacterial culture of patients was not evaluated. Thirdly, the antibiotic susceptibility test was not performed in every fungal positivity, and the echinocandin susceptibility of the strains could not be evaluated. As a result, a complete susceptibility and resistance pattern of the strains could not be evaluated.

\section{CONCLUSION}

Despite increasing rates of fungal infections in ICUs, diagnosis is still difficult due to the lack of specific symptoms, late positivity in cultures and the common occurrence of contemporaneous bacterial infections. Delayed treatment is directly related to increased mortality. Therefore, it is important to know the risk factors to identify highrisk patients and administer early antifungal treatment. The use of the Candida score for this purpose is relevant in critically ill medical patients. In the face of increasing rates of non-albicans Candida infections, knowing the local susceptibility patterns when planning preemptive treatment of candida infections is crucial. 
Ethical Approval: Ankara University's local ethical committee approved the study on March 12, 2018, with the decision number of 05-293-18.

Informed Consent: This is a retrospective study for which no formal consent is required.

Peer-review: Externally peer-reviewed

Author Contributions: Concept - M.K.B., N.D.A.; Design - M.K.B., N.D.A.; Supervision - N.D.A.; Materials - M.K.B., E.E.; Data Collection and/or Processing - M.K.B., L.T.; Analysis and/or Interpretation - M.K.B., N.D.A.; Literature Review - M.K.B., N.D.A., L.T.; Writer M.K.B., L.T., E.E., N.D.A.; Critical Reviews - L.T., E.E., N.D.A
Conflict of Interest: The authors declare no conflict of interest.

Financial Disclosure: The authors declared that this study has received no financial support.

Scientific Presentation: The present study was presented during 16th National Congress of the Turkish Society of Medical and Surgical Intensive Care as an oral presentation in Turkey on November 1-5, 2019. It has also been published in the congress abstract book: Yogun Bakım Derg 2019;10(S1):66.

The Thesis Study: Mehmet Kürsat Bilgin. İç hastalıklan yoğun bakım ünitesinde izlenen hastalarda fungal üremelerin ve infeksiyonların insidansı, mikrobiyolojik profili ve klinik özellikleri [MD thesis]. Ankara University; 2019, Thesis no: 10245071.

\section{REFERENCES}

1 Paiva JA, Pereira JM, Tabah A, Mikstacki A, de Carvalho FB, Koulenti $\mathrm{D}$ et al. Characteristics and risk factors for 28-day mortality of hospital acquired fungemias in ICUs: Data from the EUROBACT study. Crit Care. 2016;20:53. [CrossRef]

2 Calandra T, Roberts JA, Antonelli M, Bassetti M, Vincent JL. Di agnosis and management of invasive candidiasis in the ICU: An updated approach to an old enemy. Crit Care. 2016;20:125 [CrossRef]

3 Taccone FS, Van den Abeele AM, Bulpa P, Misset B, Meersseman $\mathrm{W}$, Cardoso $\mathrm{T}$, et al. Epidemiology of invasive aspergillosis in critically ill patients: clinical presentation, underlying conditions, and outcomes. Crit Care. 2015;19:7. [CrossRef]

4 Pappas PG, Kauffman CA, Andes DR, Clancy CJ, Marr KA, Ostrosky-Zeichner L, et al. Clinical practice guideline for the management of candidiasis: 2016 update by the Infectious Diseases Society of America. Clin Infect Dis. 2016;62:e1-50. [CrossRef]

5 Paramythiotou E, Frantzeskaki F, Flevari A, Armaganidis A, Dimopoulos G. Invasive fungal infections in the ICU: How to approach, how to treat. Molecules 2014;19:1085-119. [CrossRef]

6 Matthaiou DK, Christodoulopoulou T, Dimopoulos G. How to treat fungal infections in ICU patients. BMC Infect Dis 2015;15:205. [CrossRef]

7 Singh T, Kashyap AK, Ahluwalia G, Chinna D, Sidhu SS. Epidemiology of fungal infections in critical care setting of a tertiary care teaching hospital in North India: A prospective surveillance study. J Clin Sci Res. 2014;3:14-25.

8 Yapar N. Epidemiology and risk factors for invasive candidiasis. Ther Clin Risk Manag. 2014;10:95-105. [CrossRef]

9 Ostrosky-Zeichner L, Sable C, Sobel J, Alexander BD, Donowitz G, Kan V, et al. Multicenter retrospective development and validation of a clinical prediction rule for nosocomial invasive candidiasis in the intensive care setting. Eur J Clin Microbiol Infect Dis. 2007;26:271-6. [CrossRef]
10 Davis SL, Vazquez JA, McKinnon PS. Epidemiology, risk factors, and outcomes of Candida albicans versus non-albicans candidemia in nonneutropenic patients. Ann Pharmacother. 2007;41:568-73. [CrossRef]

11 Sandhu R, Dahiya S, Sayal P, Budhani D. Increased role of non-albicans Candida, potential risk factors, and attributable mortality in hospitalized patients. J Health Res Rev. 2017;4:7883. [CrossRef]

12 León C, Alvarez-Lerma F, Ruiz-Santana S, León MA, Nolla J, Jordá R, et al. Fungal colonization and/or infection in non-neutropenic critically ill patients: Results of the EPCAN observational study. Eur J Clin Microbiol Infect Dis 2009;28:233-42. [CrossRef]

13 Ayhan M. Non-nötropenik yoğun bakım hastalarında kandida kolonizasyonu ve enfeksiyonu açısından risk faktörlerinin değerlendirilmesi. [Thesis] Ankara University, School of Medicine; 2015. Turkish.

14 Ergin F, Eren Tülek N, Yetkin MA, Bulut C, Oral B, Tuncer Ertem G. Yoğun bakım ünitesinde yatan hastalarda Candida kolonizasyonunun değerlendirilmesi ve kolonizasyon indeksinin kullanilması [Evaluation of Candida colonization in intensive care unit patients and the use of Candida colonization index]. Mikrobiyol Bul. 2013;47:305-17. Turkish. [CrossRef]

15 Strollo S, Lionakis MS, Adjemian J, Steiner CA, Prevots DR. Epidemiology of hospitalizations associated with invasive candidiasis, United States, 2002-2012. Emerg Infect Dis. 2017;23:713. [CrossRef]

16 Fournier P, Schwebel C, Maubon D, Vesin A, Lebeau B, Foroni $\mathrm{L}$, et al. Antifungal use influences Candida species distribution and susceptibility in the intensive care unit. J Antimicrob Chemother. 2011;66:2880-6. [CrossRef].

17 Rodríguez D, Almirante B, Cuenca-Estrella M, Rodríguez-Tudela JL, Mensa J, Ayats J, et al. Predictors of candidaemia caused by non-albicans Candida species: Results of a population-based surveillance in Barcelona, Spain. Clin Microbiol Infect. 2010;16:1676-82. [CrossRef] 
18 Silva S, Negri M, Henriques M, Oliveira R, Williams DW, Azeredo J. Candida glabrata, Candida parapsilosis and Candida tropicalis: Biology, epidemiology, pathogenicity and antifungal resistance. FEMS Microbiol Rev. 2012;36:288-305. [CrossRef

19 Giacobbe DR, Mikulska M, Tumbarello M, Furfaro E, Spadaro M Losito AR, et al. Combined use of serum (1, 3)- $\beta$-D-glucan and procalcitonin for the early differential diagnosis between candidaemia and bacteraemia in intensive care units. Crit Care 2017;21(1):176. [CrossRef]

20 Al-Dorzi HM, Sakkijha H, Khan R, Aldabbagh T, Toledo A, Ntinika $\mathrm{P}$, et al. Invasive candidiasis in critically ill patients: A prospective cohort study in two tertiary care centers. J Intensive Care Med. 2020;35:542-53. [CrossRef]
21 Bassetti M, Garnacho-Montero J, Calandra T, Kullberg B, Dimopoulos G, Azoulay E, et al. Intensive care medicine research agenda on invasive fungal infection in critically ill patients. Intensive Care Med. 2017;43:1225-38. [CrossRef]

22 Bailly S, Leroy O, Montravers P, Constantin JM, Dupont H, Guillemot D, et al. Antifungal de-escalation was not associated with adverse outcome in critically ill patients treated for invasive candidiasis: Post hoc analyses of the AmarCAND2 study data. Intensive Care Med. 2015;41:1931-40. [CrossRef]

23 Jordà-Marcos R, Alvarez-Lerma F, Jurado M, Palomar M, Nolla-Salas J, León MA, et al. Risk factors for candidaemia in critically ill patients: a prospective surveillance study. Mycoses. 2007;50:302-10. [CrossRef] 